\title{
Functional Annotation of RIKEN Mouse cDNA Clones Using GNF Expression Atlas
}

\author{
Serge Batalov, ${ }^{1}$ Andrew I. Su, Keith A. Ching, and Colin F. Fletcher \\ Genomics Institute of the Novartis Research Foundation (GNF), San Diego, California 92121, USA
}

\begin{abstract}
Annotation of novel cDNAs relies on multiple lines of evidence, including gene structure, predicted ORFs, and predicted protein motifs. Insight into function also relies on expression profiling, through querying EST databases of direct experimentation.

High-throughput gene expression profiling, by use of spotted arrays or oligo chip methods, has become an important tool for investigating transcriptional activity. Among cDNAs predicted to encode related proteins, different expression patterns can suggest functional specialization. Additionally, common expression patterns can serve to group otherwise unrelated cDNAs. Expression profiling may be particularly useful for difficult to annotate clones, for which other lines of evidence are not available.

GNF has generated and analyzed gene expression previously from a set of 45 murine samples across a diverse list of normal tissues, organs, and cell lines probed with the Affymetrix MG-U74A chip. These data have been published (Su et al. 2002) and are available at the GNF's free and publicly accessible Web site (Gene Expression Atlas, http: / / expression.gnf.org), which integrates data visualization and curation of current gene annotations.

We identified the relationship between the RIKEN collection and MG-U74A/B/C targets by SIM4-polished BLAST alignments between 60,770 RIKEN clone sequences and 36,701 target sequences arrayed on the $\mathrm{U} 74 \mathrm{~A} / \mathrm{B} / \mathrm{C}$ chips. The results of this analysis are summarized in Table 1 . There are 25,831 RIKEN clones represented on this array set. Of these, 2994 have lower quality similarity hits at the DNA or protein level (i.e., are not automatically or easily annotated by homology).

Ten additional tissues were profiled using the Affymetrix MG-U74Bv2 and MG-U74Cv2 chips to allow for inferred functional annotation in the absence of other evidence. These tissues were chosen to give the greatest representation of gene expression by extrapolation from the results obtained with U74A. Five of the tissues are also in common with those used to probe the RIKEN microarray. The combined resources should provide an extremely comprehensive characterization of the expression data.

Figure 1 shows just two arbitrarily taken cases in which tentative annotation may be inferred from the expression profile.
\end{abstract}

\begin{tabular}{|c|c|c|c|c|c|}
\hline Chip & $\begin{array}{l}\text { Probe } \\
\text { sets }\end{array}$ & $\begin{array}{l}\text { RIKEN } \\
\text { hits }\end{array}$ & $\begin{array}{c}\text { and not } \\
\text { U74A }\end{array}$ & $\begin{array}{c}\text { and not } \\
\text { U74B }\end{array}$ & $\begin{array}{l}\text { and not easy } \\
\text { to annotate }\end{array}$ \\
\hline U74A & 12,422 & 12,199 & - & - & 454 \\
\hline U74B & 12,411 & 11,165 & 9,965 & - & 1,669 \\
\hline U74C & 11,868 & 4,138 & 3,667 & 2,926 & 821 \\
\hline
\end{tabular}

aNot counting clones with evidence class 0-4 (The FANTOM Consortium and the RIKEN Genome Exploration Research Group Phase I and II Team 2002).

\section{REFERENCES}

The FANTOM Consortium and the RIKEN Genome Exploration Research Group Phase I and Phase II Team. 2002. Analysis of the mouse transcriptome based on functional annotation of 60,770 full-length cDNAs. Nature 420: 563-573.

Su, A.I., Cooke, M.P., Ching, K.A., Hakak, Y., Walker, J.R., Wiltshire, T., Orth, A.P., Vega, R.G., Sapinoso, L.M., Moqrich, A., et al. 2002. Large-scale analysis of the human and mouse transcriptomes. Proc. Natl. Acad. Sci. 99: 4465-4470.

${ }^{1}$ Corresponding author.

E-MAIL batalov@gnf.org; FAX (858) 812-1570.

Article and publication are at http://www.genome.org/cgi/doi/10.1101/gr.1457103. 
A

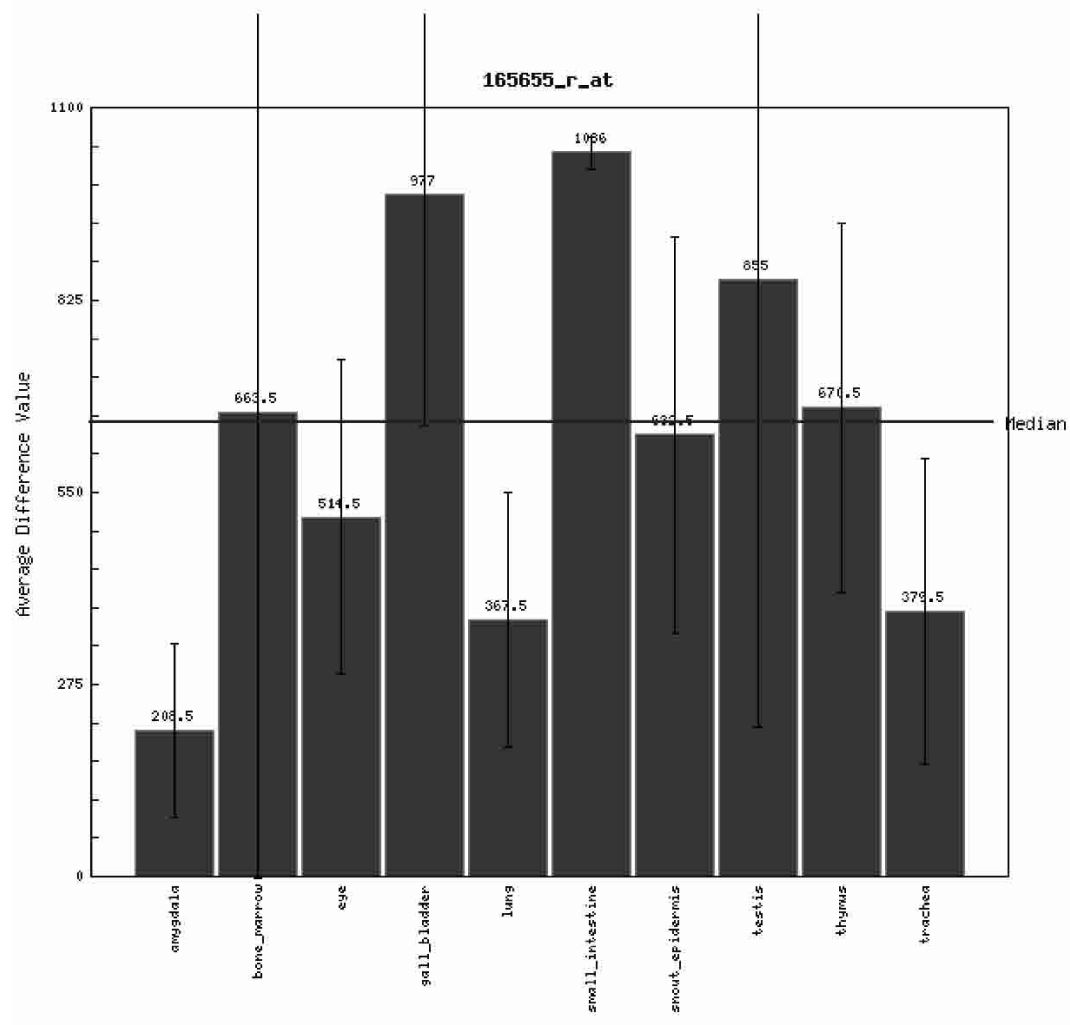

165655_r_at Original Affymetrix Annotation

AI448459:mq40a07.x1 Mus musculus cDNA, 3 end

Gurrent Annotation Thu Apr 24 19:15:04 PDT 2003

Locuslink id 56226

name espin

symbol Espn

product espin

sumfunc none

sumutary none

go actin bundling activity; ATE

binding activity; cilium; brush

border; actin cytoskeleton; parallel

actin filament bundle formation;

extannot none

phenotype none

map $480.1 \mathrm{cM}|\underline{\mathrm{MGD}}| \mathrm{G} \mid 4 \mathrm{E} 1$

maplink MGD

nm NM 019585 Notes

np $\mathrm{NP}^{-} 062531$

pubmed $12207892 \quad 11217851 \quad 11076861$

$11042159 \underline{10975527} 10588661$

10349636

NCBI MGD Human-Mouse Symteny

$h_{-}$ctix $h_{-}$id $h_{-} s y n$

$1 \quad 7161$ TF73 4 4 20062 Tpp 73

149856 WDR8 $4 \quad 59002$ W7AX8

$1 \quad 89715$ DKF2P434A196 4 56226 Eqn

111332 HBACH $4 \quad 70025$ 2410041A17R. ik

18514 KCNAB2 $4 \quad 16498$ Konb2

Unigene Expect $5 e-55$ identity $100 \%$

137 bases

ug Mm. 32006

name Espn

title espin

cytoband $480.1 \mathrm{~cm}$

chromos ome 4

expression eyeball colon lung...

B

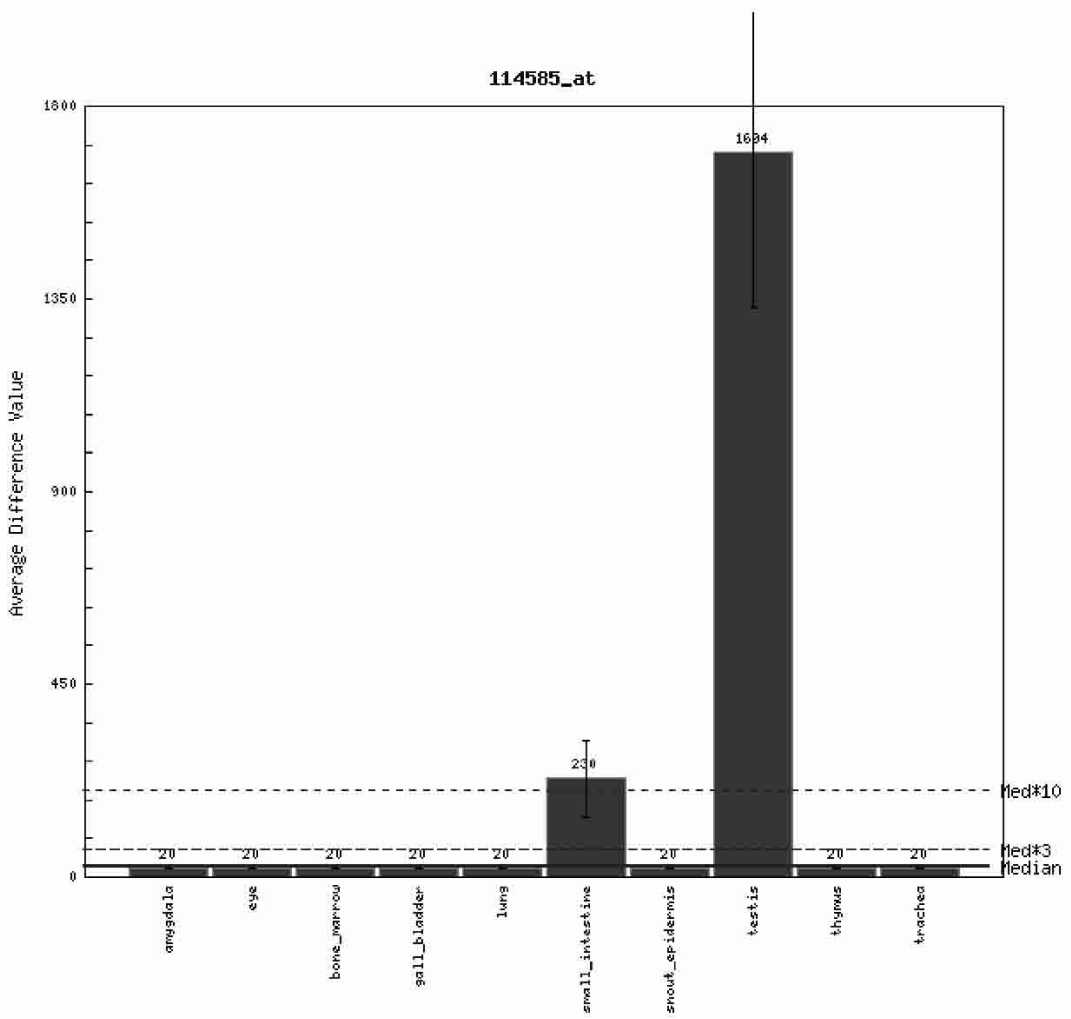

114585_at Original Affymetrix

Annotation

בW046432: UI-M-BH1-akp-d-05-0-UI . s1 Mus musculus cDNA, 3 end

Current Annotation Thu Apr 24

19:32:17 EDT 2003

Locuslink id 207175

name centrin 4

symbol LOC 207175

product centrin 4

sumfunc none

sumitiary none

go none

extannot none

phenotype none

map none

maplink none

nit NM_145825 Notes

np NP 665824

pubmed none

Unigene Expect 2 e-90 identity 1008 matchlength 181 bases Query size

181 bases

ug Mm. 25493

name LOC207175

title centrin 4

cytoband $3 \mathrm{~B}$

chromosome 3

expression visual cortex fetus

testis spermatocytes, pooled from multiple mice

18-day leptotene and zygotene

spermatocytes Testicles mammary

gland bladder

olfactory brain bone marrow heart

Figure 1 (A) RIKEN clone $0610007 F 01$ is interrogated by the probeset 165655_r_at. (B) RIKEN clones 6430560A18 and G430087M20 are associated with the probe set 114585 at with testis-specific pattern. 


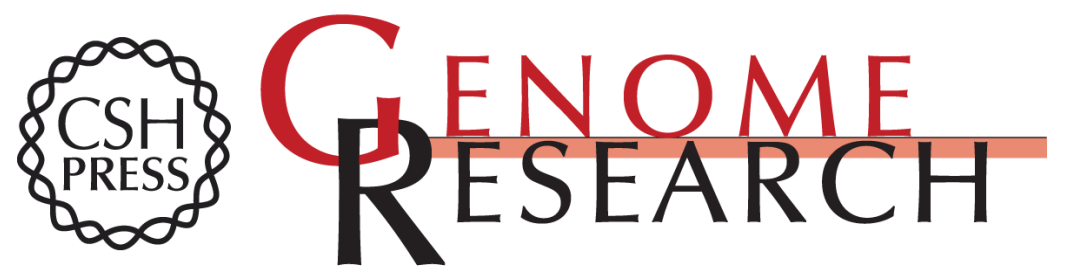

\section{Functional Annotation of RIKEN Mouse cDNA Clones Using GNF Expression Atlas}

Serge Batalov, Andrew I. Su, Keith A. Ching, et al.

Genome Res. 2003 13: 1556-1557

Access the most recent version at doi:10.1101/gr.1457103

References This article cites 2 articles, 1 of which can be accessed free at:

http://genome.cshlp.org/content/13/6b/1556.full.html\#ref-list-1

\section{License}

Email Alerting Receive free email alerts when new articles cite this article - sign up in the box at the Service top right corner of the article or click here.

\section{Affordable, Accurate Sequencing.}

To subscribe to Genome Research go to: https://genome.cshlp.org/subscriptions 